\title{
Impact of the Self-Adaptive Valve Behavior on an Array of Microfluidic Cells under Unsteady and Non-Uniform Heat Load Distributions
}

\author{
G. Laguna ${ }^{1}$, M. Vilarrubí ${ }^{1}$, M. Ibañez ${ }^{1}$, J. Rosell ${ }^{1}$, F. Badia ${ }^{1}$, H. Azarkish ${ }^{2}$, L. Michel \\ Collin $^{2}$, L. Fréchette ${ }^{2}$ and J. Barrau ${ }^{1 \dagger}$ \\ ${ }^{1}$ University of Lleida, Lleida, Catalonia,, 25001, Spain \\ ${ }^{2}$ UMI-LN2 - Interdisciplinary Institute of Technological Innovation (3IT) - University of Sherbrooke, \\ Sherbrooke, Quebec, J1K 0A5, Canada
}

†Corresponding Author Email: jerome.barrau@udl.cat

(Received May 18, 2018; accepted July 2, 2018)

\begin{abstract}
Previous studies have demonstrated that the performance of a cooling scheme based on a matrix of microfluidic cells with self-adaptive valves under unsteady and non-uniform heat load scenarios improves in terms of pumping power and temperature uniformity, compared to the ones from conventional microchannels and hybrid jet impingement/microchannel cooling devices. The behavior of the thermally dependent self-adaptive valves varies as a function of some design parameters. In this work, the impact of the valve's characteristic curve on the cooling device is assessed to establish the basic rules for the valve design. The performance of a $3 \times 3$ microfluidic cell array is numerically studied under an unsteady and non-uniform heat load scenario. The results show that the valves which open at the most elevated temperature (control temperature of $90^{\circ} \mathrm{C}$ ) reduce by $15.5 \%$ the pumping power with respect to the valves opening at $60^{\circ} \mathrm{C}$, while improving by $25.0 \%$ the temperature uniformity and reducing both the overcooling and the fatigue.
\end{abstract}

Keywords: Adaptive cooling; Temperature uniformity; Distributed cooling; Pumping power.

\section{NOMENCLATURE}

$\begin{array}{ll}b & \text { valve width } \\ e & \text { valve eccentricity } \\ h & \text { valve thickness } \\ L & \text { valve length } \\ P_{\text {pump }} & \text { hydraulic power } \\ q^{\prime \prime} & \text { heat flux } \\ Q & \text { matrix of cells, total flow rate } \\ Q_{\max } & \text { maximum flow rate (single cell) }\end{array}$

$\begin{array}{ll}R & \text { thermal resistance } \\ t & \text { time } \\ T_{\text {in }} & \text { temperature inlet } \\ \mathrm{T}_{\text {chip }} & \text { average temperature on the chip base } \\ T_{\text {chip,max }} & \text { maximum temperature on the chip base } \\ \Delta P & \text { difference of pressure } \\ \Delta T_{\text {chip }} & \text { temperature difference on the chip base }\end{array}$

\section{INTRODUCTION}

Many applications, such as electronic devices or solar concentration receivers, are submitted to increasing heat flux densities, which implies the need of cooling devices that ensure their temperature control (safety function) without decreasing drastically their compactness. Liquid cooling devices based on microchannels (Tuckerman and Pease 1981) reach these goals as they provide very low thermal resistance coefficients. Nevertheless, this technology has two main drawbacks: large pressure drops, leading to high pumping powers, and poor temperature uniformity of the cooled object, implying reliability issues (Sharma et al., 2012).

As a consequence, many papers and review articles are focused on enhanced microchannels (Dede and Liu, 2013; Khan and Fartaj, 2011; Naphon, Wiriyasart, and Wongwises, 2015) in order to deal with these drawbacks. Also other solutions, based on hybrid jet impingement/microchannel techniques have been proposed and tested experimentally (Barrau et al., 
2010, 2012; Riera et al., 2015; Sung and Mudawar, 2006). Such cooling schemes have demonstrated their capacity to obtain prefixed temperature profiles along the coolant flow path (even uniform) when tailoring at the design stage their internal geometry to the heat loads. Furthermore, the hybrid jet impingement/microchannels devices generate less pressure losses than conventional microchannels and, consequently, need lower pumping powers (Barrau et al., 2011, 2014).

These investigations have been carried out through constant and uniform boundary conditions while heat load scenarios are, for example in electronic applications, usually unsteady and non-uniform. (Riera et al., 2014) demonstrated that, at the design stage, the internal geometry can be tailored to both uniform and non-uniform heat loads in order to generate a wide range of temperature profiles. However, as the geometry is fixed, the cooling device performance is not optimum when the heat load changes, for example in a transient heat load scenario. Therefore, cooling devices are overly conservative and lead to oversized pumping powers.

In recent works, a cooling device formed by a matrix of microfluidic cells with individually variable coolant flow rate has been assessed under non-uniform and time dependent heat load scenarios (Azarkish et al., 2017; Laguna et al., 2017). The cooling scheme (Fig. 1) consists in a matrix of microfluidic cells (dimensions $1.2 \times 2.0$ $\mathrm{mm}^{2}$ ) with thermally activated microvalves (Fig. 2) (McCarthy et al., 2008), which tailor the local coolant flow rate to the local need of heat extraction capacity, avoiding overcooling and improving the temperature uniformity (Laguna et al., 2017).

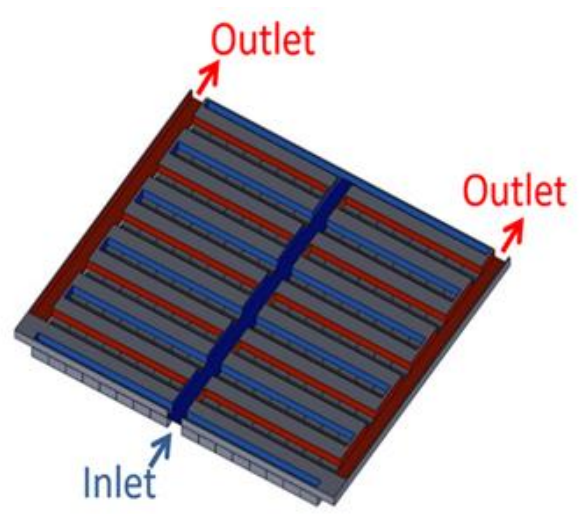

Fig. 1. Microfluidic cell matrix with distributor.

The self-adaptive valves are doubly-clamped beams, made with a high thermal expansion material with respect to the base on which they are fixed, that buckle when their temperature increases and therefore let the coolant flow through a slot located below them.

The authors demonstrated that the performance further enhanced the one of conventional microchannels. Indeed, the temperature nonuniformities were reduced by a factor of 3 while the pumping power was reduced by $89.1 \%$ (Laguna et al., 2017). These studies have been performed in ideal conditions, assuming the one dimensional approach presented by (Sharma, Tiwari, and Poulikakos 2016) and a theoretical valve with an aperture, and therefore a local flow rate, that maintains the maximum temperature of the cooled object below a given critical temperature.

However, as demonstrated by (McCarthy et al., 2007) the characteristic curves of the self-adaptive valves depend on their geometry (Fig. 3).

This behavior implies that the flow rate provided by the self-adaptive valve for a given set of boundary conditions does not correspond to the optimum one, which corresponds to the flow rate at which the maximum temperature of the cooled object is equal to the critical one. Therefore, the hypothesis of the one direction model, based on the isothermal assumption, is not verified.

In this study, a numerical model is developed to assess the performance of the matrix of microfluidic cells with self-adaptive microvalves. This model, which includes the conduction between adjacent cells, allows the assessment of the impact of spreading on the overall performance. Furthermore, the impact of the microvalve characteristic curves is evaluated to establish design criteria for this component.

\section{DESCRIPTION OF THE COOLING DEVICE}

\subsection{Geometry}

In this work, a microfluidic cell with an external size of $2 \times 1.2 \mathrm{~mm}^{2}$ is used (Fig. 4). Its internal geometry consists in 6 tailored microchannels that increase the local heat extraction capacity along the flow path, according to previous studies (Laguna et al., 2017), counteracting the coolant temperature increase in the same direction.

The coolant (water in this study) enters from a distributor through a $1 \times 0.1 \mathrm{~mm}^{2}$ inlet slot located on the cell's cold side (heat load opposite side) and exits by the outlet slot, with the same dimensions as the inlet, connected to the exit path of the distributor. The valve is located at the outlet, near the heat load surface (hereafter chip surface), to approximate its temperature to the chip one $(x, y$, $z=0)$ and, therefore, to tailor the flow rate to this parameter.

\subsection{Numerical Models}

For all the numerical simulations, the coupling between heat transfer and fluid flow is included in the COMSOL Multiphysics CFD model in a steady state study with laminar flow model (maximum Reynolds number: 89). 
(a)

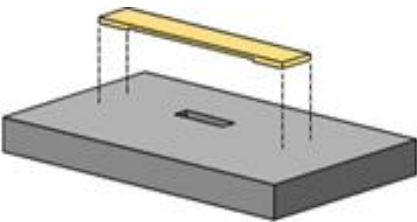

(c) Hot

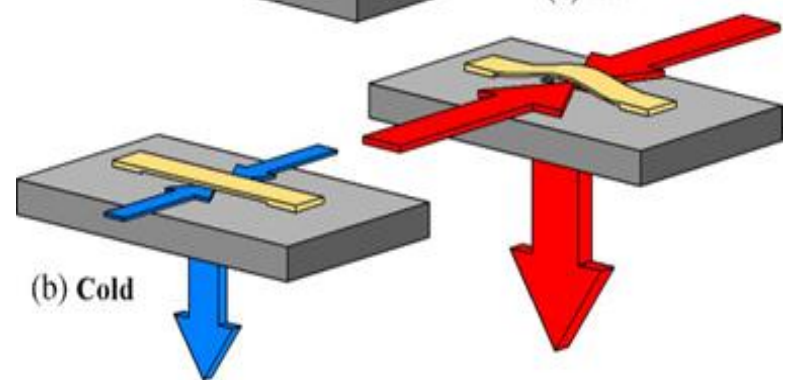

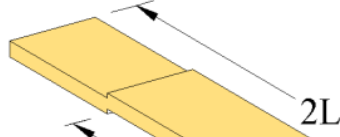

d)

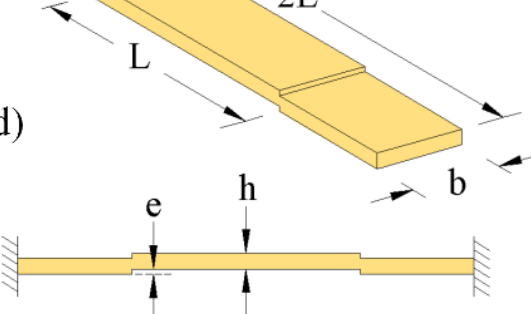

Fig. 2. Microvalve a) placement, b) cold position c) hot position and d) valve parameters (McCarthy $e t$ al., 2008).

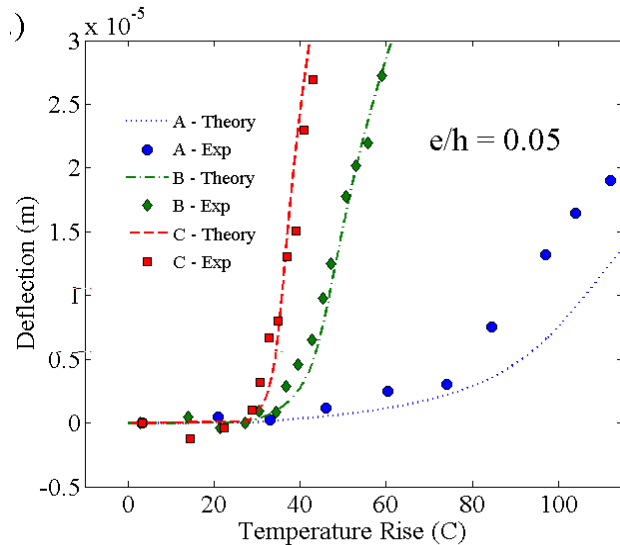

Fig. 3. Valve deflection results with $h=30 \mu \mathrm{m}, \mathrm{e}=$ $1.5 \mu \mathrm{m}$ and $\mathrm{L}=1 \mathrm{~mm}(\mathrm{~A}), \mathrm{L}=\mathbf{2} \mathrm{mm}(\mathrm{B}) \mathrm{L}=3 \mathrm{~mm}$ (C) (McCarthy et al., 2007).

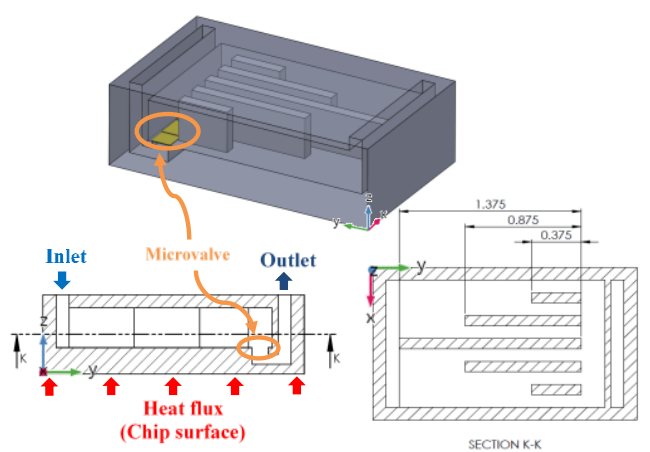

Fig. 4. MC6T design (dimensions in $\mathrm{mm}$ ).

At a first stage, a numerical study is carried out to assess the maximum flow rate needed to maintain the chip temperature below $100^{\circ} \mathrm{C}$ at the most demanding boundary conditions (heat flux: 300 $\mathrm{W} / \mathrm{cm}^{2}$; inlet coolant temperature: $50^{\circ} \mathrm{C}$ ). For this steady-state study, the boundary conditions of the numerical models considered are indicated in Fig. 5.

A mesh sensitivity analysis has been carried out and the final model accounts with 603921 elements.

At a second stage, a numerical study is carried out with 9 microfluidic cells in a $3 \times 3$ cell matrix (Fig. 6 ). This model has been implemented in order to take into account the conduction between adjacent microfluidic cells. Indeed, for non-uniform heat load scenarios, the characteristic curve of the valve generates some temperature uniformities that cause spreading.

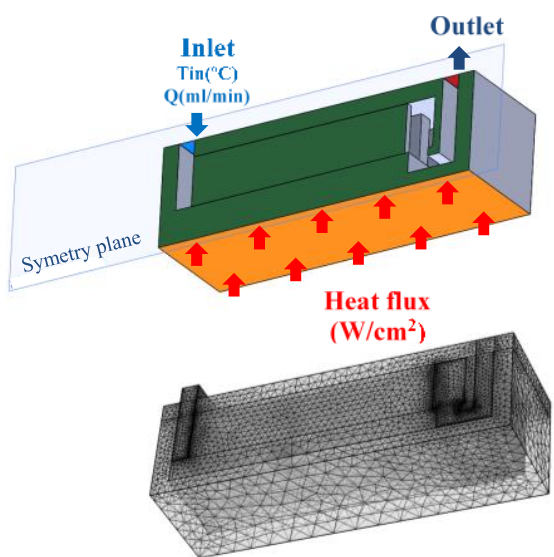

Fig. 5. Numerical model. a) Boundary conditions, b) Mesh used.

The performance of the microfluidic cell array is assessed for three microvalve models. For the three models, (hereafter, V60, V75 and V90) the microvalves open linearly from control temperature $\left(60^{\circ} \mathrm{C}, 75^{\circ} \mathrm{C}\right.$ and $90^{\circ} \mathrm{C}$, respectively) until complete opening is reached at $100^{\circ} \mathrm{C}$ (Fig. 7). The maximum cell flow rate (Qmax) corresponds to the one obtained in the previous simulation in the most demanding situation. When the boundary conditions vary with respect to the worst ones, the flow rate is tailored to the base temperature through the temperature dependent microfluidic valve function (hereafter characteristic curve). Below the control value, a residual flow rate ( $1 \%$ of $Q \max$ ) enters the cooling cell, as this kind of microvalve can't close completely. This general trend of valve function corresponds to the results obtained previously (Fig. 3, McCarthy et al., 2007). 


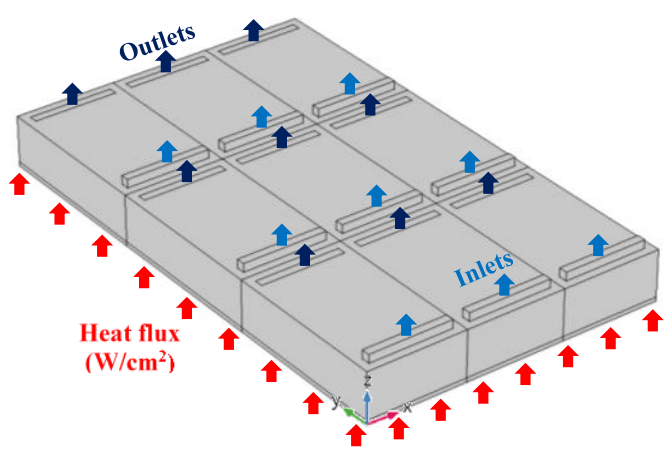

Fig. 6. Boundary conditions of the numerical model.

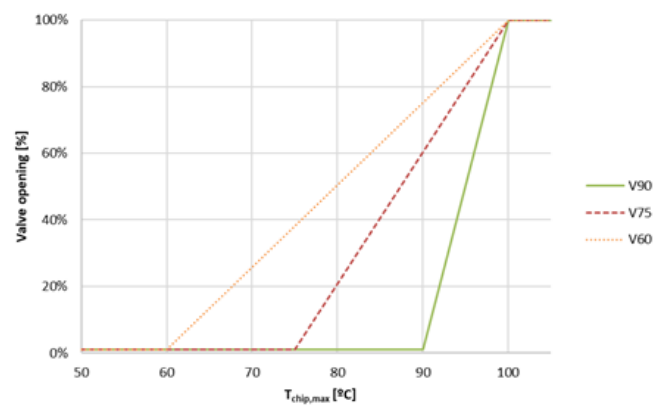

Fig. 7. Microvalves aperture percentage versus temperature (characteristic curves).

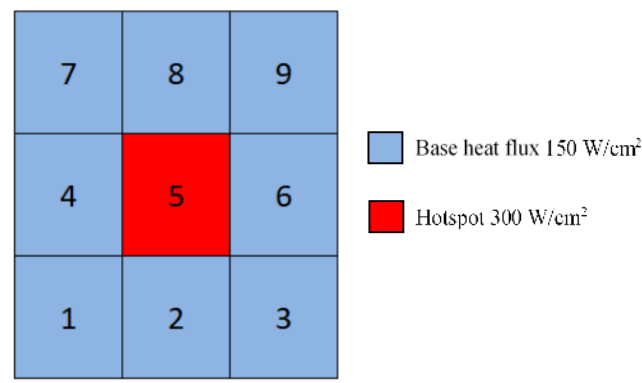

Fig. 8. Heat flux distribution at $t_{1}$ on the $3 \times 3$ microfluidic cell array.

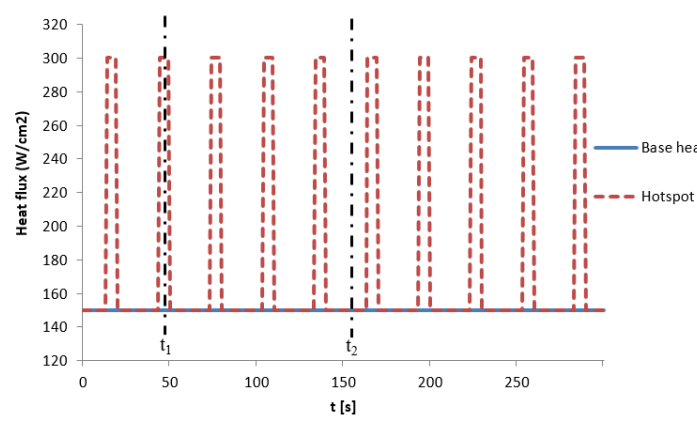

Fig. 9. Time dependence of the heat loads.

\subsection{Unsteady and Non-Uniform Heat Load Scenario}

A non-uniform and time dependent head load scenario, including hotspot and base heat flux zones, is applied to the $3 \times 3$ microfluidic cell array (Fig. 8 and 9). The hotspot $\left(300 \mathrm{~W} / \mathrm{cm}^{2}\right)$, that fully covers the central microfluidic cell, is activated periodically $\left(t_{l}\right)$ while the surrounding microfluidic cells are submitted to a base heat flux of 150 $\mathrm{W} / \mathrm{cm}^{2}$. When the hotspot is not activated, all the cells are submitted to the base heat flux of 150 $\mathrm{W} / \mathrm{cm}^{2}\left(t_{2}\right)$.

Finally, in order to assess the global performance of the cooling device, the steady state results corresponding to the boundary conditions of $t_{1}$ and $t_{2}$ are integrated along a 5 minutes' time period.

\section{RESULTS AND DISCUSSION}

\subsection{Maximum flow Rate Assessment for a Single Microfluidic Cell in Extreme Boundary Conditions}

The maximum flow rate $\left(Q_{\max }\right)$ needed to maintain the maximum temperature of the heated area below $100{ }^{\circ} \mathrm{C}$, and assessed for a heat flux of $300 \mathrm{~W} / \mathrm{cm}^{2}$ and an inlet coolant temperature of $50^{\circ} \mathrm{C}$ (extreme boundary conditions), is $3.9 \mathrm{~mL} / \mathrm{min}$ (Table 1). In these conditions, the thermal resistance coefficient of the cooling device, assessed through Eq. (1), is $1.6 \cdot 10^{-5} \mathrm{~m}^{20} \mathrm{C} / \mathrm{W}$.

$R=\frac{T_{\text {chip }}-T_{\text {in }}}{q^{\prime}}$

Table 1 Thermo-hydraulic performance of the cooling cell in worst conditions $\left(300 \mathrm{~W} / \mathrm{cm}^{2}\right.$ and inlet temperature $50^{\circ} \mathrm{C}$ )

\begin{tabular}{|c|c|c|c|c|}
\hline $\begin{array}{c}T_{\text {chip }} \\
\left({ }^{\circ} \mathrm{C}\right)\end{array}$ & $\begin{array}{c}T_{\text {chip, max }} \\
\left({ }^{\circ} \mathrm{C}\right)\end{array}$ & $R\left(\mathrm{~m}^{2 \circ} \mathrm{C} / \mathrm{W}\right)$ & $\begin{array}{c}\Delta T_{\text {chip }} \\
\left({ }^{\circ} \mathrm{C}\right)\end{array}$ & $\begin{array}{c}\Delta P \\
(\mathrm{~Pa})\end{array}$ \\
\hline 98.3 & 100.0 & $1.6 \cdot 10^{-5}$ & 5.1 & 1384 \\
\hline
\end{tabular}

Compared to conventional microchannels or other internal geometries of the microfluidic cells (Laguna et al., 2017), the tailored microchannels allow obtaining a relatively low maximum temperature difference across the microfluidic cell base $\left(5.1^{\circ} \mathrm{C}\right)$. The maximum chip temperature is not located near the outlet, but in the center of the microfluidic cell, due to the effect on the tailored microchannel internal geometry (Fig. 10).

3.2 Performance of the Microfluidic Cell Array for Uniform and Non-Uniform Heat fluLoads

The flow rate of each of the microfluidic cells is now assessed considering the characteristic curve of the self-adaptive microvalves (V60, V75 and V90) and the thermal conduction across the entire computational domain. The thermal maps of the $3 \times 3$ microfluidic cells array, obtained for the 3 microvalve models at $t_{1}$ and $t_{2}$, show that their characteristic curves have an impact on both the average temperature and the temperature uniformity (Fig. 11).

When the heat flux is uniform $\left(t_{2}\right)$, the temperature distribution is similar for the 3 microvalve models, but the average temperature increases with the control temperature of the valve (Fig. 12). For the non-uniform heat flux distribution $\left(t_{1}\right)$, a similar trend is found, but a detailed analysis of the results 
Table 2 Thermo-hydraulic performance of the cooling $3 \times 3$ matrix cell

\begin{tabular}{|c|c|c|c|c|c|c|c|c|c|}
\hline \multirow{3}{*}{} & Valve & $\begin{array}{c}T_{\text {in }} \\
\left({ }^{\circ} \mathrm{C}\right)\end{array}$ & $\begin{array}{c}Q \\
(\mathrm{~mL} / \mathrm{min})\end{array}$ & $\begin{array}{c}T_{\text {chip }} \\
\left({ }^{\circ} \mathrm{C}\right)\end{array}$ & $\mathrm{T}_{\text {chip, } \max }\left({ }^{\circ} \mathrm{C}\right)$ & $\begin{array}{c}R \\
\left(\mathrm{~m}^{2} \mathrm{C} / \mathrm{W}\right)\end{array}$ & $\begin{array}{c}\Delta T_{\text {chip }} \\
\left({ }^{\circ} \mathrm{C}\right)\end{array}$ & $\begin{array}{c}\Delta P \\
(\mathrm{~Pa})\end{array}$ & $\begin{array}{c}P_{\text {pump }} \\
(\mathrm{W})\end{array}$ \\
\hline \multirow{4}{*}{$t_{1}$} & $\mathrm{~V} 60$ & 50.0 & 20.2 & 87.1 & 96.5 & $2.2 \cdot 10^{-5}$ & 14.0 & 817 & $2.75 \cdot 10^{-4}$ \\
\cline { 2 - 12 } & $\mathrm{V} 75$ & 50.0 & 18.6 & 89.3 & 97.9 & $2.4 \cdot 10^{-5}$ & 13.3 & 818 & $2.54 \cdot 10^{-4}$ \\
\cline { 2 - 11 } & $\mathrm{V} 90$ & 50.0 & 16.3 & 93.4 & 99.8 & $2.6 \cdot 10^{-5}$ & 10.5 & 908 & $2.47 \cdot 10^{-4}$ \\
\hline \multirow{4}{*}{$t_{2}$} & $\mathrm{~V} 60$ & 50.0 & 18.3 & 86.0 & 88.6 & $2.4 \cdot 10^{-5}$ & 5.0 & 559 & $1.70 \cdot 10^{-4}$ \\
\cline { 2 - 11 } & $\mathrm{V} 75$ & 50.0 & 16.5 & 88.7 & 91.3 & $2.6 \cdot 10^{-5}$ & 5.2 & 482 & $1.32 \cdot 10^{-4}$ \\
\cline { 2 - 11 } & $\mathrm{V} 90$ & 50.0 & 14.1 & 93.2 & 95.8 & $2.9 \cdot 10^{-5}$ & 5.3 & 390 & $9.18 \cdot 10^{-5}$ \\
\hline
\end{tabular}

(Table 2) shows a different behavior for the central microfluidic cells depending on the microvalve model V60, V75 and V90.

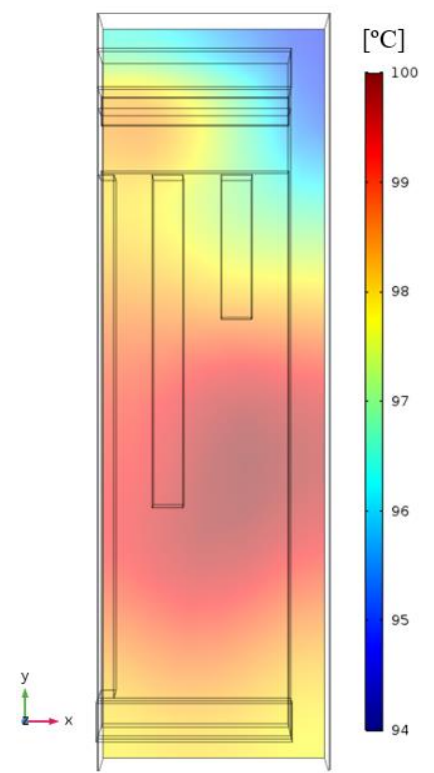

Fig. 10. Chip temperature distribution for extreme boundary conditions and maximum flow rate.

On the one hand, the global flow rate (sum of all the single microfluidic flow rates) is decreased by 19.3 $\%$ (Table 2) when microvalve V90 is used instead of V60 (at $t_{1}$ ). Furthermore, V90 valve brings the maximum temperature closer to the critical one $\left(100^{\circ} \mathrm{C}\right)$ and improves the temperature uniformity by $25 \%$. These results show that the elevated slope of the V90 characteristic curve is adequate to limit the overcooling and improves the temperature uniformity.

On the other hand, the flow rate of the central microfluidic cell (at $t_{1}$ ) is higher for V90 than for the other valves, causing a highest pressure drops in this cell and so, at the entire hydraulic circuit, as the cells are hydraulically connected in parallel. This result is due to the fact that the elevated slope of the V90 characteristic curve generates an improvement of the temperature uniformity of the array. Therefore, the spreading effect decreases and the central cell (submitted to the highest heat flux) with V90 valve has to absorb nearly all the heat that is fed into it. Meanwhile, for the other valves (V60 and V75), the temperature non-uniformities generate thermal conduction heat fluxes from the central cell to the surrounding ones (Fig. 13), and the flow rates needed to maintain the temperature below the critical one are lowers. Quantitatively, the central cell with the valve V60, V75 and V90 deliver by spreading to the other cells $28.14 \%$, $24.93 \%$ and $15.97 \%$ respectively.

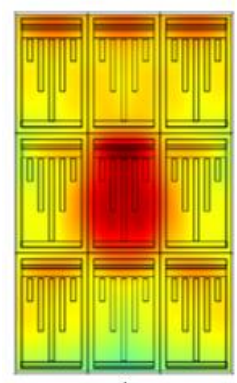

a)

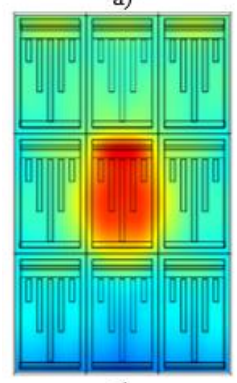

c)

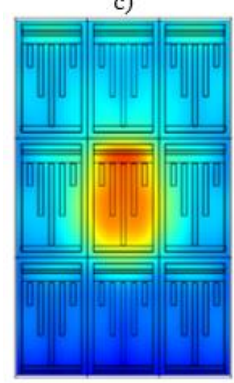

e)

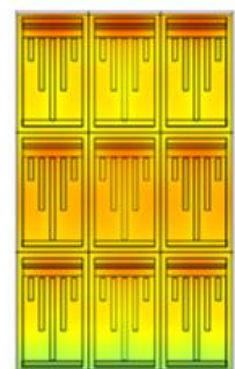

b)

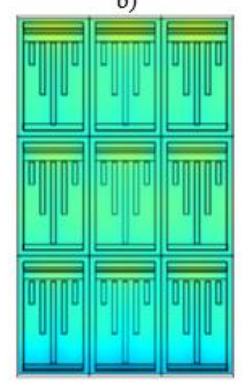

d)

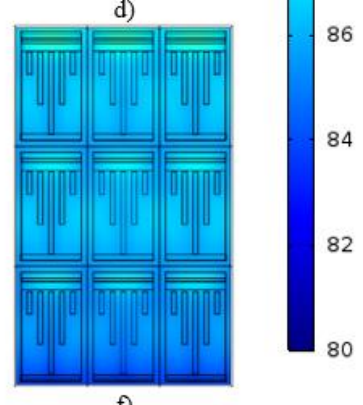

f)
Fig. 11. Thermal map of the chip surface for a) $\left.\left.\mathrm{V90} ; t_{1}, \mathrm{~b}\right) \mathrm{V90} ; t_{2}, \mathrm{c}\right) \mathrm{V75} ; t_{1}$, d) V75; $t_{2}$, e) V60; $t_{1}$ and f) $V 60 ; t_{2}$.

So, for the non-uniform heat flux distribution $\left(t_{1}\right)$, the impact of the lower global flow rate of V90 cell on the hydraulic pumping power $\left(P_{\text {pump }}\right)$, with respect to V60 and V75, is partially counterbalanced by its higher pressure drop. On the contrary, for the uniform heat load $\left(t_{2}\right)$, both the global flow rate and the pressure drops are lower for 
the V90 microfluidic cell, lowering the pumping power needed with respect to the other 2 valves.

In all the cases considered, the thermal resistance coefficient $(R)$ of the $3 \times 3$ array of microfluidic cells increases slightly with respect to the single cell, as the flow rate per cell is lower.

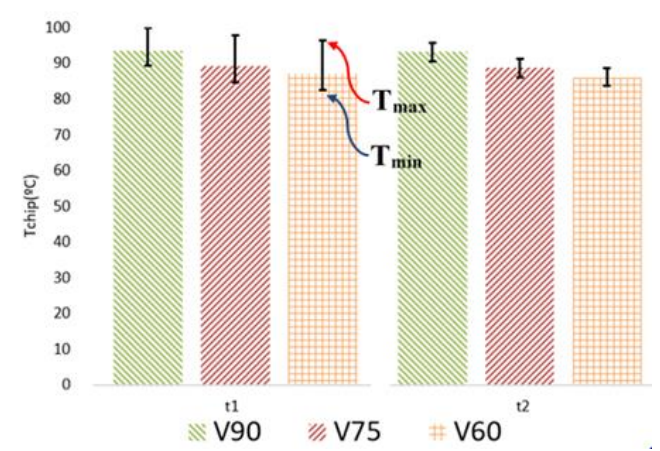

Fig. 12. Average chip temperature and its variation across the entire chip surface for $t_{1}$ and $t_{2}$ for each valve.
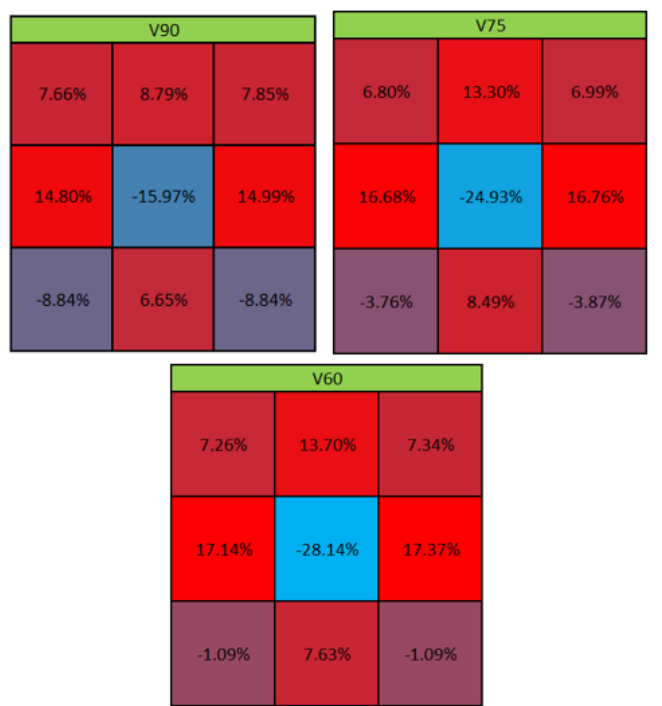

Fig. 13. Power absorbed by each cell compared with the delivered power $(\%)$.

\subsection{Performance of the Microfluidic Cell Array in Unsteady and Non-Uniform Heat Loads}

The total flow rate of the $3 \times 3$ array of microfluidic cells varies depending on the heat load distribution at each moment, through the characteristic curve of the self-adaptive microvalve (Fig. 14). As exposed in the previous chapter, for both the uniform and non-uniform heat loads, the flow rate needed to reach the temperature restriction, $100^{\circ} \mathrm{C}$ on the chip surface, decreases when the valve control temperature increases. The average flow rates of the $3 \times 3$ array of microfluidic cells, along the time considered, with V90 and V75 valves are, respectively, $77.9 \%$ and $90.5 \%$ of the one with V60 valve. This result indicates that, from the flow rate point of view, the design of the valve has to be focused to reach a quick aperture through a nearly discontinuous manner (perfect beam, (McCarthy et al., 2007)).

The cooling device with the V90 valve maintains the maximum temperature of the chip closer to the critical one than the other studied valves, indicating that it reduces the overcooling of the system (Fig. 15). Furthermore, the variation of the maximum temperature of the chip surface, for both the uniform and the non-uniform heat load, is lower in the case of the cooling device with the V90 valve $\left(4.1^{\circ} \mathrm{C}\right)$ than for $\operatorname{V60}\left(7.9^{\circ} \mathrm{C}\right)$ and $\operatorname{V75}\left(6.6^{\circ} \mathrm{C}\right)$. This result indicate that the $\mathrm{V} 90$ valve will induce less fatigue due to the thermal cycling than the other 2 studied valves.

The valve opening range is an indicator of the efficiency of the cooling solution. If the opening value is far from the maximum temperature, it will produce overcooling so will be less energy efficient. For this reason, the flow during all the integration time with the V60 valve is higher than with the other valves (Fig. 14).

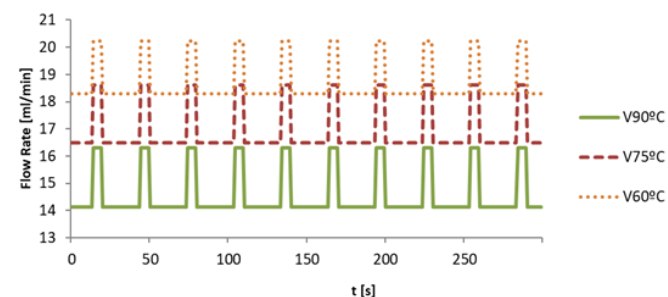

Fig. 14. Total flow rate along the time period.

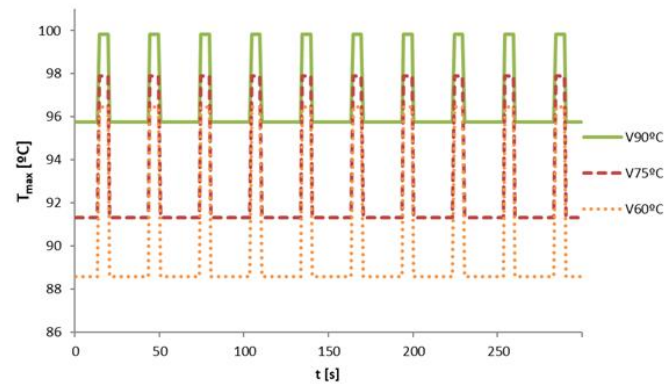

Fig. 15. Maximum temperature of the chip surface along the time period.

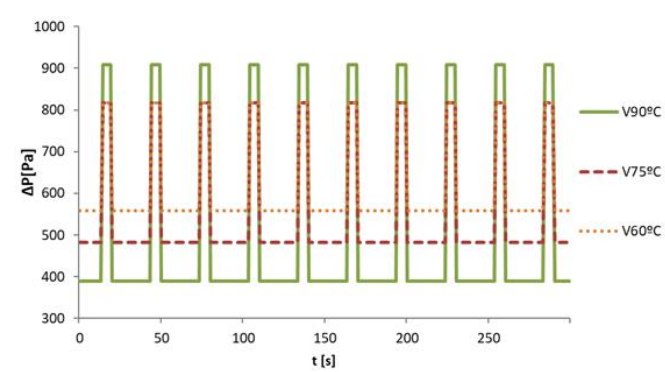

Fig. 16. Pressure drop along the time period.

For the non-uniform heat load $\left(t_{1}\right)$, the flow rate of the central cell is respectively $91.21 \%, 91.58 \%$ and $98.08 \%$ for V60, V75 and V90 of the maximum one $\left(Q_{\max }\right)$. The higher flow rate in the central cell with V90 implies, for the non-uniform heat load, higher 
pressure drops.

The assessment of the time dependent total flow rate and pressure drops provides the hydraulic pumping power trend along the period considered (Fig. 17), assessed through Eq. (2).

$$
\text { Ppump }=\Delta P \cdot Q
$$

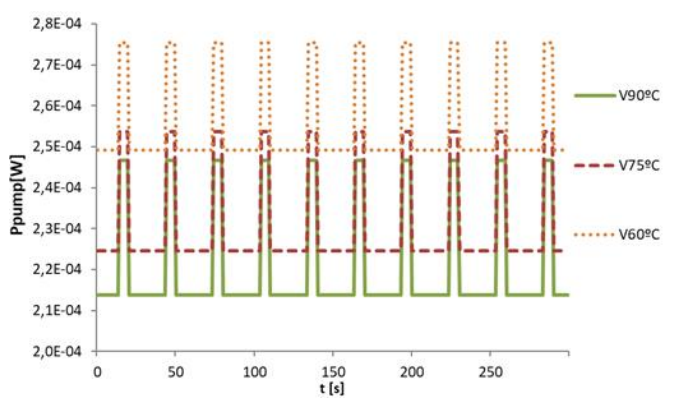

Fig. 17. Pumping power of the whole cooling device along the time period.

For the same temperature limitation, the average power consumption, assessed over a 5 minute period, of the V75 and V60 are respectively $4.53 \%$ and $15.49 \%$ higher than the V90 power consumption. The V90 valve tailors better the local flow rates to the heat extraction needs, maintaining the chip temperature closer to the temperature limitation. Also, as explained previously, the pressure drop is increased at $t_{1}$ for V90 due to the lower spreading between the microfluidic cells, but this drawback is counterbalanced by the flow rate reduction.

The pumping energy for the studied cooling device with V90, V75 and V60 valves $\left(E_{\text {valve }}\right)$ is, respectively, $27 \%, 29 \%$ and $32 \%$ of the energy needed by the same cooling device but without the self-adaptive valves ( $\left.E_{\text {no-valve }}\right)$, so without the capacity to tailor the flow rate distribution to unsteady and non-uniform heat load scenarios (Fig. 18). Furthermore, V90 characteristic curve provides the highest temperature uniformity to the cooled surface (Fig. 18), indicating that a sudden change of the double clamped beam actuating as the valve is more appropriate than a progressive one.

These results would vary as a function of the heat load scenario characteristics.

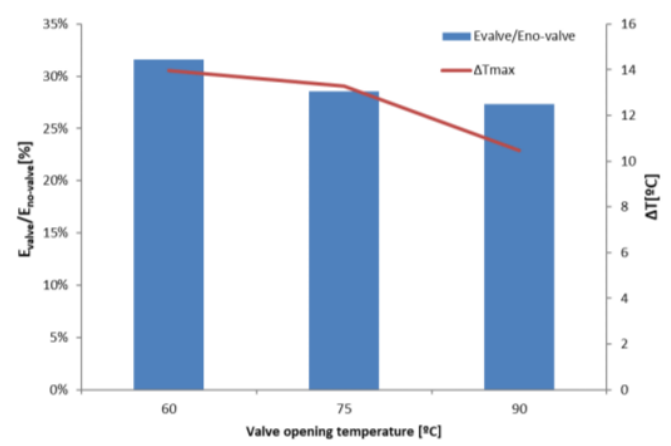

Fig. 18. $E_{\text {valve }} / \boldsymbol{E}_{\text {no-valve }}$ and temperature uniformity depending on microvalve control temperature.

\section{CONCLUSION}

The impact of the behavior of thermally dependent self-adaptive valves on the performance of a cooling scheme based on a matrix of microfluidic cells with individually variable coolant flow rate is assessed. The self-adaptive valves are doublyclamped beams, made with a high thermal expansion material with respect to the base on which they are fixed, that buckle when their temperature increases and therefore let the coolant flow through a slot located below them. Previous studies show that the deflection of the beam, and therefore the variation of the flow rate through the valve, can present different behaviors (from discontinuous to continuous nonlinear) as a function of some design parameters.

After showing that the unidirectional heat flux hypothesis, assumed by some authors, is not verified due to the non-ideal behavior of the selfadaptive valves, a $3 \times 3$ array of microfluidic cells is proposed to assess the performance of the cooling device, taking into account the conduction between cells, for different valve characteristic curves. For a given unsteady and non-uniform heat load scenario, targeting the criteria of limiting the maximum temperature of the heated surface below $100^{\circ} \mathrm{C}$, the time-dependent distribution of the microfluidic cell flow rates is assessed.

For the uniform heat flux distribution, both the flow rate and the pressure drop of the device using V90 valve, the one with the highest control temperature, is reduced with respect to V60 valve, by $23 \%$ and $30 \%$, respectively.

However, for the non-uniform heat flux distribution, the flow rate of the cooling device with the V90 valve is still lower than the other studied ones, but its pressure drop is higher, counteracting partially the gains, in terms of pumping power, related to the lower flow rate of V90 device. Indeed, while the central microfluidic cell, submitted to the highest heat flux, of the devices with V60 and V75 valves spreads a relatively large part of the received heat to the surrounding cells (25 and 28\%, respectively), V90 characteristic curve provides a distribution of the microfluidic cell flow rates that reduces the temperature variation across the heated surface and, therefore, the thermal conduction between cells (spreading of $15 \%$ to the surrounding cells).

These behaviors imply that the energy needed for pumping along the time period considered is, for V90, V75 and V60, only $27.3 \%, 28.6 \%$ and $31.6 \%$ respectively of the one needed by a similar cooling device without microfluidic valves. Apart from its benefits in terms of pumping power, the higher slope of the V90 characteristic curve provides a better temperature uniformity of the cooled surface, limits the overcooling and reduces the temperature variations along the heat load scenario.

\section{ACKNOWLEDGEMENTS}

The research leading to these results has been 
performed within the STREAMS project (www.project-streams.eu) and received funding from the European Community's Horizon 2020 program under Grant Agreement n ${ }^{\circ} 688564$.

\section{REFERENCES}

Azarkish, H., J. Barrau, P. Coudrain, G. Savelli, L.M. Collin and L.G. Frechette (2017). SelfAdaptive Microvalve Array for Energy Efficient Fluidic Cooling in Microelectronic Systems. 2017 16th IEEE Intersociety Conference on Thermal and Thermomechanical Phenomena in Electronic Systems (ITherm, 2017): 522-29.

Barrau, J., D. Chemisana, J. Rosell, L. Tadrist and M. Ibañez (2010). An Experimental Study of a New Hybrid Jet Impingement/Micro-Channel Cooling Scheme. Applied Thermal Engineering 30(14-15), 2058-2066..

Barrau, J., A. Perona, A. Dollet and J. Rosell (2014). Outdoor Test of a Hybrid Jet Impingement/Micro-Channel Cooling Device for Densely Packed Concentrated Photovoltaic Cells. Solar Energy 107, 113-121.

Barrau, J., J. Rosell, D. Chemisana, L. Tadrist and M. Ibañez (2011). Effect of a Hybrid Jet Impingement/Micro-Channel Cooling Device on the Performance of Densely Packed PV Cells under High Concentration. Solar Energy 85(11): 2655-2665.

Barrau, J., M. Omri, D. Chemisana, J. Rosell, M. Ibañez and L. Tadrist (2012). Numerical Study of a Hybrid Jet Impingement/Micro-Channel Cooling Scheme. Applied Thermal Engineering 33-34(1), 237-245.

Dede, E.M. and Y. Liu (2013). Experimental and Numerical Investigation of a Multi-Pass Branching Microchannel Heat Sink. Applied Thermal Engineering 55(1-2), 51-60.

Khan, M.G. and A. Fartaj (2011). A Review on Microchannel Heat Exchangers and Potential Applications. International Journal of Energy Research 35(7), 553-582.

Laguna, G., H. Azarkish, M. Vilarrubí, M. Ibañez, J. Rosell, Y. Betancourt, J. Illa, L.-M. Collin, J. Barrau, L. Fréchette, P. Coudrain and G. Savelli (2017). Microfluidic Cell Cooling System for Electronics. Thermal Investigations of Integrated Circuits and Systems (September): 1-4.

McCarthy, M., N. Tiliakos, V. Modi and L.G. Fréchette (2007). Thermal Buckling of Eccentric Microfabricated Nickel Beams as Temperature Regulated Nonlinear Actuators for Flow Control. Sensors and Actuators, A: Physical 134(1), 37-46.

McCarthy, M., N. Tiliakos, V. Modi and L.G. Fréchette (2008). Temperature-Regulated Nonlinear Microvalves for Self-Adaptive MEMS Cooling. Journal of Microelectromechanical Systems 17(4), 9981009.

Naphon, P., S. Wiriyasart and S. Wongwises (2015). Thermal Cooling Enhancement Techniques for Electronic Components. International Communications in Heat and Mass Transfer 61, 140-145.

Riera, S., J. Barrau, A. Perona, A. Dollet, J.I. Rosell and Fréchette, L. CPV Receiver under Non Uniform Illumination Profile. AIP Conference Proceedings 1616, 207-210.

Riera, S., J. Barrau, M. Omri, L.G. Fréchette and J.I. Rosell (2015). Stepwise Varying Width Microchannel Cooling Device for Uniform Wall Temperature: Experimental and Numerical Study. Applied Thermal Engineering 78, 30-38.

Sharma, C.S., S. Zimmermann, M.K. Tiwari, B Michel and D. Poulikakos (2012). Optimal Thermal Operation of Liquid-Cooled Electronic Chips. International Journal of Heat and Mass Transfer 55(7-8), 1957-1969.

Sharma, C.S., M.K. Tiwari and D. Poulikakos (2016). A Simplified Approach to Hotspot Alleviation in Microprocessors. Applied Thermal Engineering 93, 1314-1323.

Sung, M. K. and I. Mudawar (2006). Experimental and Numerical Investigation of Single-Phase Heat Transfer Using a Hybrid JetImpingement/Micro-Channel Cooling Scheme. International Journal of Heat and Mass Transfer 49(3-4), 682-694.

Tuckerman, D. B. and R. F. W. Pease (1981). HighPerformance Heat Sinking for VLSI. IEEE Electron Device Letters 2(5), 126-129. 